\title{
Trasplante de Aloinjerto de Páncreas en Perros con Diabetes Mellitus Experimental
}

\author{
ROLANDO MENDÍVIL'. FAUSTO GARMENDIA². CECILIA YERÉN². WILLIAM TORRES². \\ 'Departamemos de Cirugía y Laboratorio Experimenal, Hospital Nacional Dos de Mayo. 'Instituto de Investigaciones \\ Clínicas, Facultad de Medicina UNMSM. Departamento de Medicina, Hospital Nacional Dos de Mayo \\ Trabajo ganador del Primer Pluesto en el XXXI Congreso Peruano e Internacional de la Academia Nacional de Cirugía
}

\begin{abstract}
RESUMEN
OBJETIVOS: Evaluar la eficacia del trasplante de aloinjerto de páncreas (TAP) en perros con diabetes mellitus experimental (DME) inducida por aloxano. MÉTODOS: Se utilizó 63 perros mestizos; de ellos, 33 para conseguir las mejores condiciones experimentales; los otros 30 fueron divididos en 3 grupos de 10 cada uno: a) controles, sólo se les produjo DME; b) receptores con DME, a los que se les realizó el TAP; y c) donantes de páncreas. RESULTADOS: El control de glicemia fue total en el $50 \%$ de los receptores y parcial en el $30 \%$, obteniendo una eficacia global del TAP en relación al control de $80 \%$. El tiempo de sobrevida post TAP fue 19,9 \pm 6,2 horas. El estudio anatomopa tológico mostró signos de rechazo hiperagudo. Las principales complicaciones fueron: hemorragia digestiva alta, neumonía aspirativa, pancreatitis necrotizante con peritonitis generalizada, hipoglicemia y perros que no despertaron de la anestesia. CONCLUSIONES: EI TAP fue eficaz para controlar la glicemia en el $80 \%$ de los animales; sin embargo, la sobrevida fue pobre, lo cual podxía estar relacionado al efecto tóxico del aloxano y al rechazo hiperagudo. Se requieren más estudios experimentales para mejorar la sobrevida.
\end{abstract}

Palabras claves: Diabetes Mellitus Experimental; Transplante de Pancreas.

\section{PANCREAS ALLOGRAFT TRANSPLANTATION IN DOGS WITH ALLOXAN-INDUCED DIABETES MELLITUS \\ SUMMARY}

OBJECTYVE: To evaluate the efficacy of pancreas allograft transplantation (PAT) in dogs with alloxan-induced diabetes mellitus. METHODS: A total of 63 mongrel dogs were used; 33 were employed to improve our surgery skills, and another 30 were divided into: Group A (control group, 10 dogs) which had EDM only; group B (receptor group, 10 dogs) which underwent PAT; and group C (donor group, 10 dogs). RESULTS: Glycemic control were achieved completely $(50 \%)$, and partially $(30 \%)$. The average survival rate of dogs was $19,9 \pm 6,2 \mathrm{~h}$. Anatomopathological specimens were consistent with hyperacute rejection. The main complications were upper gastrointestinal bleeding, aspirative pneumonia, necrotic pancreatitis with diffuse peritonitis, hypoglicemy and $20 \%$ of dog did not awake after anesthesia. CONCLUSIONS: PAT resulted in good glycemic control in $80 \%$ of EDM dogs. Nevertheless, the survival rate was very short, possibly related to toxic effects of alloxan or hyperacute rejection. Further experimental studies should be done in order to obtain a longer survival length.

Key words: Diabetes Mellitus, Experimental; Pancreas Trasplantation.

Correspondencia:

Dr. Rolando Mendivil Zapata.

Instimuo de Investigaciones Clínicas UNMSM.

Hospiral Nacional Dos de Mavo. Av. Grau s/n. Lima I - Perí

E-mail: posmmast@hos2man:pe 


\section{INTRODUCCIÓN}

En 1927 se realizó el primer trasplante exitoso de páncreas llevado a cabo en perros por Gayet y Guillaumine ('). Cuatro décadas después, Kelly y Liliehei realizaron el primer trasplante de páncreas en seres humanos en la Universidad de Minnesota, EE.UU. Desde esa época hasta la actualidad se han realizado investigaciones tanto en modelos animales como en seres humanos y se ha logrado obtener una sobrevida del injerto de $70 \%$ y del paciente de $95 \%$, consideradas a un año de observación $\left.{ }^{2 \cdot 4}\right)$.

Han pasado cerca de siete décadas desde el primer trasplante de páncreas y hasta el momento en el Perú no se ha efectuado ninguno en seres humanos, así como tampoco en modelos animales.

En nuestro país, la tasa de prevalencia de diabetes mellitus tipo 1 es de $0,94 / 100000$ habitantes y la incidencia anual de $0,6 / 100000$ habitantes $\left({ }^{5}\right)$. Estas cifras deben ser aún mayores, tomando en cuenta que existe un elevado subregistro de pacientes.

El presente trabajo tiene por objetivo principal determinar la eficacia del trasplante de aloinjerto de páncreas en perros con diabetes mellitus experimental y efectuar así un primer acercamiento a la técnica quirúrgica y al tratamiento inmunosupresor para evitar el rechazo, que posteriormente permita su empleo en humanos con diabetes mellitus insulinodependiente. Se inicia así la investigación experimental del trasplante de páncreas en el Perú.

\section{MATERIAL Y MÉTODOS}

El presente trabajo es un estudio de tipo experimental con grupo control. Se realizó intervenciones quirúrgicas (trasplante de aloinjerto de páncreas) con un seguimiento de los receptores hasta su fallecimiento. Se efectuó estudios anatomopatológicos en todos los animales.

Se utilizó 63 perros mestizos para establecer las condiciones experimentales más apropiadas. De este grupo se utilizó 7 perros para el reconocimiento de la anatomía quirúrgica, 33 para estandarización de la dosis de aloxano y 17 perros para el adiestramiento de la técnica quirúrgica. Los otros 30 perros fueron utilizados para el trasplance de aloinjerto de páncreas (TAP) propiamente dicho, dividiéndolos en 3 grupos ( 10 cada uno): controles (grupo A), receptores (grupo B) y donantes (grupo C).

\section{Grupo A}

Fue utilizado como grupo control al cual se le produjo diabetes mellitus experimental (DME). Los perros fueron mantenidos con glicemias normales mediante la administración de insulina cristalina (Humulin $C^{\otimes}$. Eli Lilly) hasta el día que se realizó el TAP a los perros del grupo receptor, con la finalidad de comparar las glicemias de los perros con DME sin tratamiento y los perros con DME sometidos a tratamiento quirúrgico (TAP).

\section{Grupo B}

En el cual se realizó el TAP, previa producción de DME de la misma manera que al grupo anterior: Se administró insulina cristalina (Humulin $\mathrm{C}^{\circledR}$, Eli Lilly) los días previos al TAP, según los requerimientos para mantener una glicemia normal. Además se instaló una terapia antimicrobiana, antitrombótica e inmunosupresora según protocolo previamente diseñado.

\section{Grupo C}

Fue el grupo donante del páncreas a trasplantar en los perros del grupo $B$.

Se administró tratamiento antiparasitario con albendazol $100 \mathrm{mg}$ a todos los animales.

El peso de los perros varió entre 10 y $30 \mathrm{~kg}$. Las funciones vitales mostraron los siguientes rangos: frecuencia cardiaca (FC): $92-140$ lat/min (VN: 80- 140 lat/ $\mathrm{min}$ ), frecuencia respiratoria (FR): $21-33 \mathrm{resp} / \mathrm{min}$ (VN: $20-40 \mathrm{resp} / \mathrm{min}$ ) y temperatura rectal $\mathrm{T}^{\circ}: 37-39^{\circ} \mathrm{C}$ (VN: $37-39^{\circ} \mathrm{C}$ ). Se obtuvieron muestras de sangre total de venas periféricas (cefálica) a fin de constatar el estado de salud mediante hemogramas, glicemia $(77,4 \pm 11,4$ $\mathrm{mg} / \mathrm{dL})$, urea $(34,4 \pm 19 \mathrm{mg} / \mathrm{dL})$ y creatinina $(1,22 \pm$ $0,2 \mathrm{mg} / \mathrm{dL}$ ). Los grupos sanguíneos fueron " $\mathrm{O}$ " $\mathrm{Rh}(-)$ (90\%) y "A" Rh (-) (10\%). Las pruebas de compatibilidad se realizaron entre el suero del perro donante y los glóbulos rojos del receptor, siendo compatibles en el $100 \%$ de casos.

Para producir la DME, se ensayaron las siguientes dosis de aloxano tetrahidratado: $65,100,130,150 \mathrm{mg} /$ 
$\mathrm{kg}$ i.v. y finalmente se optó por la dosis de $150 \mathrm{mg} / \mathrm{kg}$ i.v., que se administró tres días antes del trasplante, diluido en $100 \mathrm{~mL}$ de suero fisiológico, lentamente y en ayunas, en un tiempo no menor de 1 minuto. La solución es sensible a la luz, por lo que fue protegida con macerial oscuro.

El diagnóstico de diabetes mellitus se realizó con niveles de glicemia iguales o mayores a $200 \mathrm{mg} / \mathrm{dL}$ en sangre cotal, utilizando la técnica de la glucosa-oxidasa con cintas reactivas (Haemoglucotest ${ }^{\circledR}$ ), medidas en un glucómetro Accucheck II.

La glicemia se mantuvo dentro de lo normal con la administración de insulina cristalina (Humulin $\mathrm{C}^{\star}$, Eli Lilly) a la dosis de 0,15 UI/kg por vía subcutánea tres veces al día, 15 minutos antes de las comidas principales.

El TAP se realizó utilizando la técnica de trasplante total, que consiste en remover la cabeza, cuerpo y cola del páncreas del donante para ser injertado en el receptor (Figuras $N^{\circ}$ i y 2 ). Las anastomosis vasculares fueron realizadas entre los vasos esplénicos del donador y los iliacos del receptor. La secreción pancreática exocrina fue manejada a través del drenaje vesical mediante una pancreatocistostomía (Figura $\mathrm{N}^{\circ} 3$ ).

Se aplicó anestesia general a los grupos B y C, que constó de un período preanestésico, obtenido con clorhidrato de ketamina $8-10 \mathrm{mg} / \mathrm{kg}$ i.m. (Ketalar ${ }^{\circledR}$, Parke Davis), diazepan $1 \mathrm{mg} / \mathrm{kg}$ i.m. (Valium ${ }^{\circledR}$, Roche) y atropina al $1 / 1000(0,5 \mathrm{mg})$, administrados 30 a 45 minutos antes del periodo anestésico de mantenimienro. La anestesia se mantuvo con una solución de 500 mg de ketamina en $250 \mathrm{~mL}$ de dextrosa al $5 \%$ (Sol. ketamina: $1 \mathrm{~mL}=20$ gotas $=2 \mathrm{mg}$ ). El goteo inicial fue 120 golas por minuto durante $2-3$ minutos, luego se inició la dosis de mantenimiento para obtener un buen plano de anestesia quirrúrgica con un goteo de 20 gotas por minuto durante toda la intervención.

El TAP se consideró eficaz cuando los niveles de glicemia disminuyeron a valores normales (control total: $80-100 \mathrm{mg} / \mathrm{dL}$ ) o por debajo de $200 \mathrm{mg} / \mathrm{dL}$ (contro. parcial) sin utilización de insulina exógena.

Como terapia antimicrobiana se administró cefalotina $16,6 \mathrm{mg} / \mathrm{kg}$ i.v. (Keflin ${ }^{\circledR}$, Eli Lilly) y @entamicina $1 \mathrm{mg} / \mathrm{kg}$ i.v. (Gentalyn ${ }^{(}$. Schering-Plough) 12 horas antes del TAP y cada 8 horas en el día operatorio. Se asoció ketoconazol $3,3 \mathrm{mg} / \mathrm{kg}$ v.o.

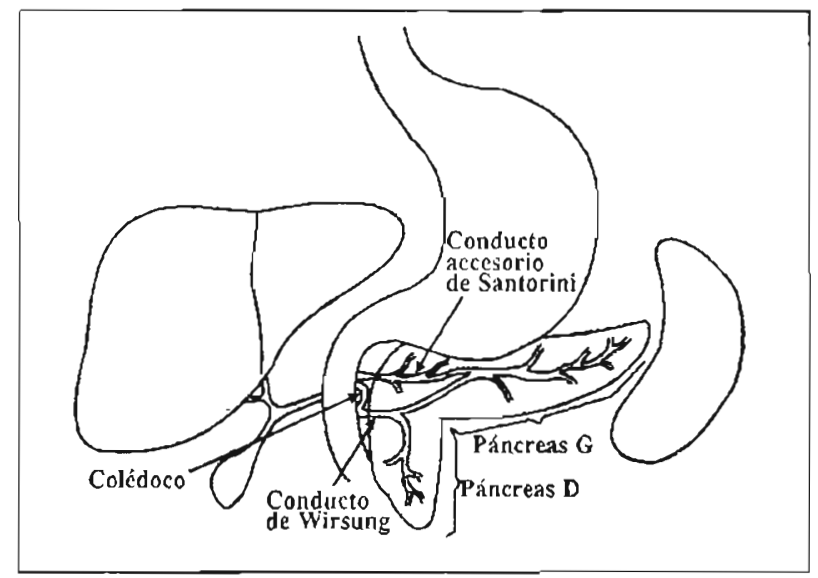

Fig. $N^{\circ}$ 1.- Anatomía del páncreas canino.

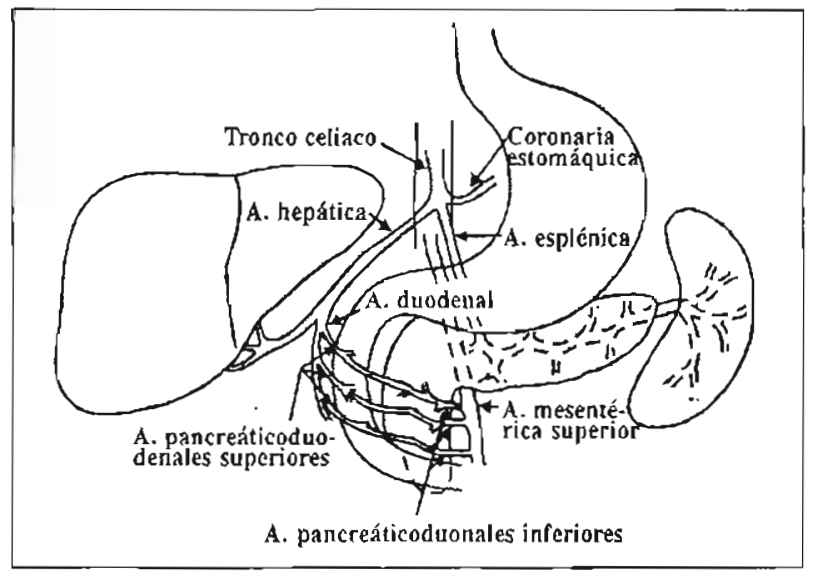

Fig. $N^{\circ}$ 2.- Irrigación del páncreas canino.

(Oxonazol ${ }^{\circledR}$, Abeefe) en el primer día posoperatorio. A partir del segundo día hasta el final del seguimiento se administró cotrimoxazol 2,7/13,3 (TMP/SMX) mg/kg v.o. (Bactrim ${ }^{\circledR}$, Roche) y ketoconazol (Oxonazol Abeefe) a la dosis ya referida.

La terapia inmunosupresora fue iniciada 12 horas antes de realizar el TAP con un esquema de tres fármacos: metilprednisolona $2 \mathrm{mg} / \mathrm{kg}$ i.v. (Solumedrol ${ }^{\circledR}$, Upjohn), azatioprina $5 \mathrm{mg} / \mathrm{kg}$ v.o. (Lab. Carrión) y ciclosporina $8 \mathrm{mg} / \mathrm{kg}$ v.o. (Sand-inmune ${ }^{\oplus}$, Sandoz). En el intraoperatorio se administró una dosis de metilprednisolona $8 \mathrm{mg} / \mathrm{kg}$ i.v., para luego continuar en el posoperatorio nuevamente con un esquema de tres fármacos: metilprednisolona $2 \mathrm{mg} / \mathrm{kg} /$ día i.v. en los tres primeros días, el cuarto día se pasó a su equivalente en 

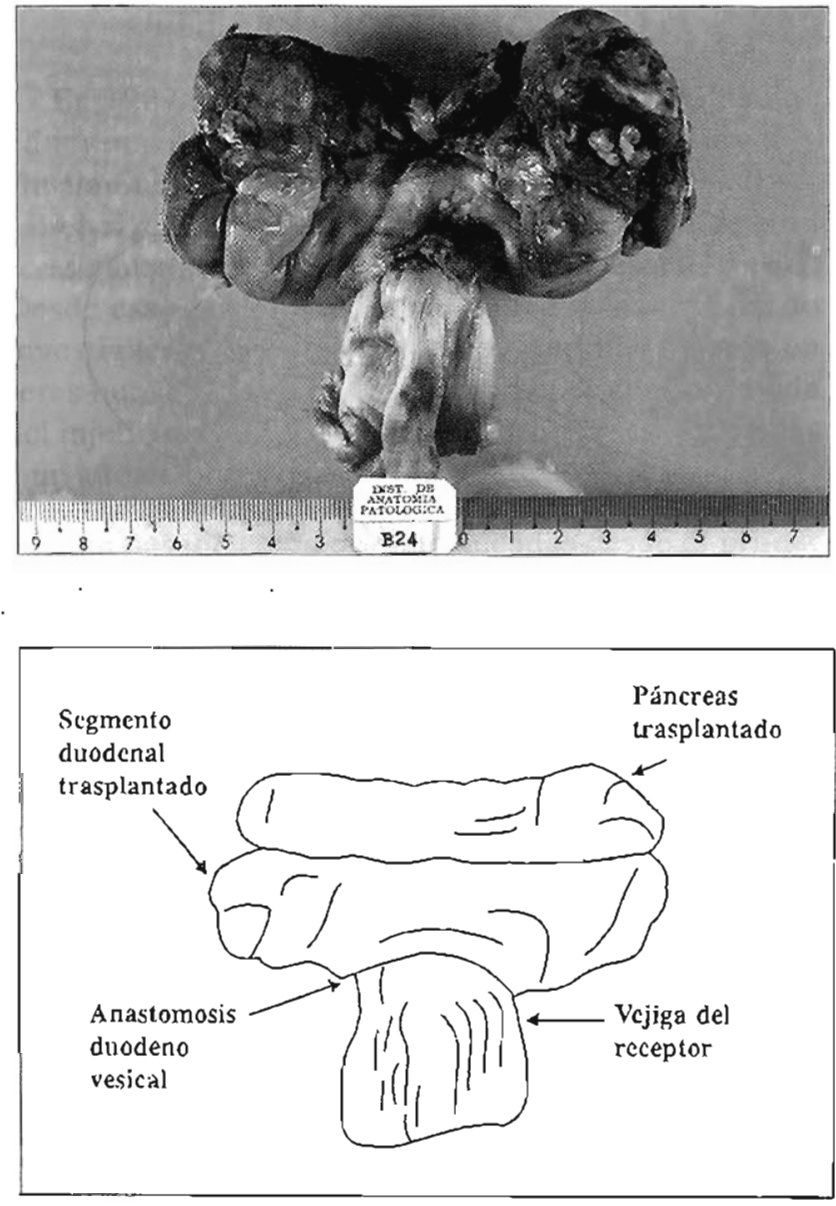

Fig. $N^{\circ}$ 3.- Pieza macroscópica (panel superior) y esquema (panel inferior) de trasplante de aloinjerto de páncreas.

prednisona $2,5 \mathrm{mg} / \mathrm{kg} /$ día v.o. (Meticorten $^{\circledR}$, Schering Plough), dosis que se mantuvo por dos días, a partir del cual se disminuyó gradualmente a razón de $0,5 \mathrm{mg} /$ $\mathrm{kg} /$ día hasta alcanzar en cuatro días la dosis de $0,5 \mathrm{mg} /$ $\mathrm{kg} / \mathrm{dí}$, que fue la dosis de mantenimiento; azatioprina $2 \mathrm{mg} / \mathrm{kg} / \mathrm{dia}$ v. o. y ciclosporina $6 \mathrm{mg} / \mathrm{kg} / \mathrm{dí}$ v.o.

Para la prevención de la trombosis se utilizó terapia antiagregante plaquetaria con dipiridamol (Persantin ${ }^{\star}$, Boehringer) y aspirina (Ascriptin ${ }^{\$}$, Química Suiza). En el preoperatorio ( 12 horas antes del trasplante), la dosis de dipiridamol fue $3,3 \mathrm{mg} / \mathrm{kg}$ v.o. y aspirina 10,8 $\mathrm{mg} / \mathrm{kg}$ v.o. En el intraoperatorio y posoperatorio las dosis fueron $1,25 \mathrm{mg} / \mathrm{kg}$ v.o. tres veces al día y 4,17 $\mathrm{mg} / \mathrm{kg}$ v.o. por día, respectivamente.
Luego de realizar el trasplante de páncreas, se realiz6 el control horario de la glicemia tanto a los perros del grupo receptor como a los del grupo control, hasta el día en el que fallecieron, a fin de comparar ambas glicemias y evaluar sus variaciones.

Se efectuó el estudio anatomopatológico del páncreas trasplantado a fin de conocer las alteraciones del tejido pancreático y las complicaciones del TAP. Se utilizó las tinciones de hematoxilina-eosina (HE), Ac. peryódico de Schiff (PAS) y tricrómico de Masson. En los cortes histologicos de páncreas trasplantado se estudió la arquitectura del tejido, presencia de amiloide, tipo de infiltrado leucocitario y el estado de los acinis serosos e islotes de Langerhans.

Se realizó el análisis estadístico de los resultados utilizando la prueba t de Student y $\mathrm{X}^{2}$, considerándose como valor estadísticamente significativo un valor de $p<0,05$

\section{RESULTADOS}

\section{Diabetes Experimental}

Con las dosis de aloxano tetrahidratado de 65, 100 , 130 y $150 \mathrm{mg} / \mathrm{kg}$, se obtuvo los siguientes porcentajes de diabetes mellitus experimental (DME) permanente: $0 ; 55,5 ; 60$ y $100 \%$, respectivamente, en un período de tiempo de 24 a 48 horas post-inyección i.v. de aloxano (Tabla $\left.N^{\circ} 1\right)$.

Tabla $N^{\circ}$ 1.- Diabetes mellitus experimental permanente (DME-P) en perros con diferentes dosis de aloxano.

\begin{tabular}{rcrrr}
\hline Dosis & Perros & \multicolumn{2}{c}{ DME-P } & Total \\
\cline { 3 - 4 } $\mathrm{mg} / \mathrm{kg}$ & $\mathrm{n}$ & $\mathrm{si}$ & $\mathrm{no}$ & $\%$ \\
\hline 65 & 4 & 0 & 4 & 0,0 \\
100 & 9 & 5 & 4 & 55,5 \\
130 & 10 & 6 & 4 & 60,0 \\
150 & 10 & 10 & 0 & 100,0 \\
Total & 33 & 21 & 12 & \\
\hline
\end{tabular}


Tabla $N^{\circ}$ 2.- Glicemias pre y post TAP en perros con diabetes mellitus experimental.

\begin{tabular}{ccccccccccccc}
\hline & \multicolumn{10}{c}{ Perro $N^{\circ}$} & & \\
\cline { 2 - 8 } Glicemia & 01 & 02 & 03 & 04 & 05 & 06 & 07 & 08 & 09 & 10 & $\bar{X}$ \\
\hline Pre TAP & 430 & 800 & 800 & 433 & 800 & 490 & 800 & 433 & 800 & 494 & 628,0 \\
Post TAP & 148 & 204 & 36 & 800 & 110 & 25 & 67 & 142 & 85 & 300 & $191,7^{*}$
\end{tabular}

TAP: Trasplante de aloinjerto de páncreas.

De los 12 perros que no desarrollaron DME permanente, 4 la desarrollaron en forma transitoria ( 48 a 72 horas) y 8 no llegaron a desariollarla. De los 4 perros con DME transitoria, 2 correspondieron a la dosis de $100 \mathrm{mg} / \mathrm{kg}$ y 2 a la dosis de $130 \mathrm{mg} / \mathrm{kg}$. De estos 4 perros, 3 fueron resistentes a dosis sucesivas e incrementadas de aloxano $(100 ; 130$ y $150 \mathrm{mg} / \mathrm{kg})$.

La DME en los perros receptores y controles se demostró con la medición de glicemia basal y postaloxano, cuya diferencia fue significativa según la prueba t de Student $(p<0,001)$.

\section{Trasplante de Páncreas}

Una vez establecidas las condiciones experimentales más apropiadas, se procedió al trasplante de páncreas, que comprendió 3 fases:

1. Fase: Extracción de órgano del donante (Promedio: 2,15 horas).
$* p<0,001$.

2० Fase: Enfriamiento del órgano (Promedio: $30 \mathrm{mi}$ nutos).

$3^{\circ}$ Fase: Injerto del órgano al receptor (Promedio: 3,31 horas).

\section{Eficacia del TAP}

Se encontró que en el $30 \%$ de los casos se controló parcialmente la glicemia y en el $50 \%$ de casos, ésta se controló totalmente; concluyéndose que la eficacia global del TAP fue $80 \%\left(X^{2}<0,47\right)$.

Se encontró diferencia estadísticamente significativa al comparar las glicemias pre y postrasplante de los perros del grupo receptor $(p<0,001)$ (Tabla $\left.N^{\circ} 2\right)$.

Al comparar" las glicemias más bajas encontradas post-TAP en el grupo receptor y grupo control, se encontró disminución estadísticamente significativa $(p<$ 0,001 ) de la glicemia en el grupo receptor (Tabla $N^{\circ} 3$ ).

Tabla $N^{\circ}$ 3.- Glicemias post TAP en perros con diabetes mellitus experimental.

\begin{tabular}{|c|c|c|c|c|c|c|c|c|c|c|c|}
\hline \multirow[b]{2}{*}{ Glicemia } & \multicolumn{10}{|c|}{ Perro $N^{\circ}$} & \multirow[b]{2}{*}{$\bar{X}$} \\
\hline & 01 & 02 & 03 & 04 & 05 & 06 & 07 & 08 & 09 & 10 & \\
\hline Grupo Control & 800 & 800 & 800 & 800 & 800 & 800 & 800 & 800 & 800 & 800 & 800,0 \\
\hline Grupo Receptor & 148 & 204 & 36 & 800 & 110 & 25 & 67 & 142 & 85 & 300 & $191,7 *$ \\
\hline
\end{tabular}


Tabla $N^{\circ}$ 4.- Glicemia basal antes de la DME y post TAP en perros con diabetes mellitus experimental.

\begin{tabular}{|c|c|c|c|c|c|c|c|c|c|c|c|}
\hline \multirow[b]{2}{*}{ Glicemia } & \multicolumn{10}{|c|}{ Perro $N^{\circ}$} & \multirow[b]{2}{*}{$\bar{X}$} \\
\hline & 01 & 02 & 0.3 & 04 & 05 & 06 & 07 & 08 & 09 & 10 & \\
\hline Basal & 77 & 107 & 79 & 71 & 75 & 70 & 82 & 66 & 72 & 75 & 77,0 \\
\hline Post TAP & 148 & 204 & 36 & 800 & 110 & 25 & 67 & 142 & 85 & 300 & $191,7 *$ \\
\hline
\end{tabular}

TAP: Trasplante de aloinjerto de páncreas.

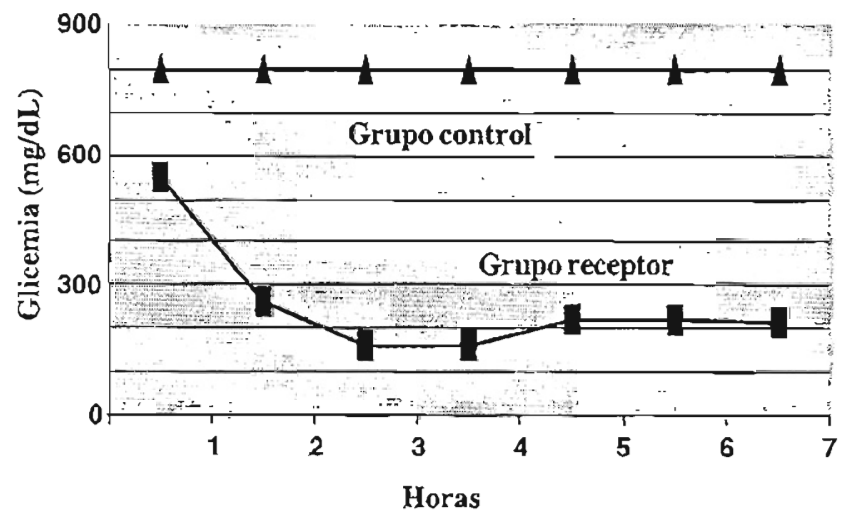

Fig. $N^{\circ}$ 4.- Glicemia horaria postrasplante de aloinjerto de páncreas.

No se encontró diferencia estadísticamente significativa entre los valores de glicemia basal pre-aloxano y glicemia postrasplante (Tabla $\mathrm{N}^{\circ} 4$ ).

El estudio de la glicemia en las seis primeras horas postrasplante mostró una disminución significativa en los niveles de los perros del grupo receptor del TAP en comparación con los del grupo control, variación que fue más notoria durante las dos primeras horas postTAP, luego de las cuales los valores fueron aumentando discretamente hasta la sexta hora postrasplante ( $F i-$ gura $\mathrm{N}^{\circ} 4$ ).

El tiempo de sobrevida post-TAP varió entre 6 y 72 horas con un promedio de 19,9 horas. El tiempo de sobrevida de los perros del grupo control tuvo un rango de 3 a 6 días, evolucionando con glicemias mayores o iguales a $800 \mathrm{mg} / \mathrm{dL}$.
$* p>0,95$.

No fue posible realizar el dosaje de amilasa urinaria por dificultad técnica en la recolección de la orina.

\section{Anatomía Patológica}

El estudio anatomopatológico del páncreas trasplantado mostró en todos los perros rechazo hiperagudo con diferentes grados de severidad, encontrándose distorsión moderada de su arquitectura en el $50 \%$ de los casos, severa en el $33 \%$ y leve en el $17 \%$. En el $50 \%$ de los casos, las células acinares y de los islotes de Langerhans mostraron proceso de lisis celular, mientras el otro $50 \%$ mostró necrosis pancreática masiva (Figura $N^{\circ} 5$ ). Se encontró congestión vascular y hemorragia intersticial en el $33 \%$ de los casos. En el $50 \%$

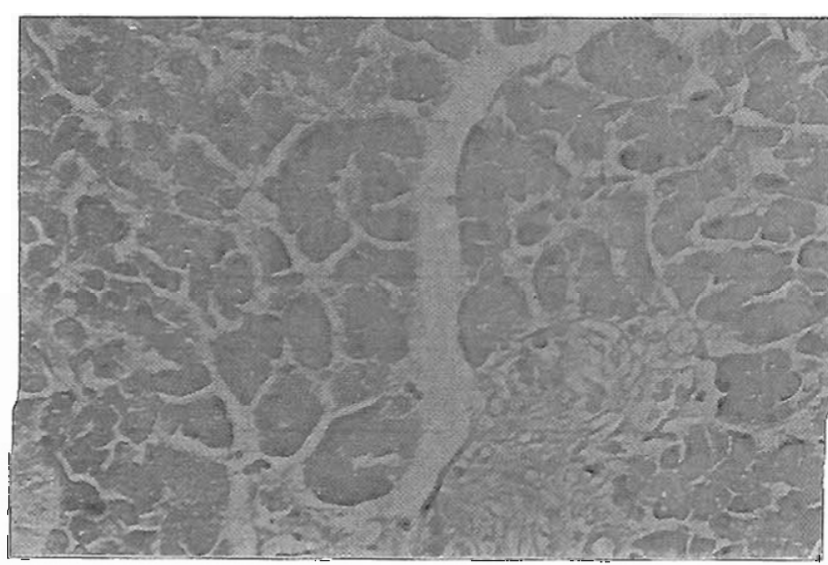

Fig. N5.- Microscopía del páncreas trasplantado (PAS 400X). Rechazo hiperagudo de páncreas trasplantado con islote de Langerhans hipocelular. 
se halló infiltrado inflamatorio, donde el $33 \%$ correspondió a polimorfonucleares y el $17 \%$ a mononucleares.

La arquitectura del riñón se encontró con leve distorsión en el $66 \%$ de los casos, con severa distorsión en el $17 \%$ y normal en el $17 \%$. En el $67 \%$ de los casos se encontró glomerulonefritis membranoproliferativa y en el 33\% necrosis glomerular hemorrágica (Figura $\mathrm{N}^{\circ}$ 6). En todos los casos se halló congestión vascular en la médula renal.

En la totalidad de los casos se encontró leve distorsión de la arquitectura pulmonar, con zonas de atelectasia alternadas con áreas de enfisema. En el 50\% de los casos se observó infiltrado mononuclear y congestion vascular.

La arquitectura del hígado se encontró con severa distorsión en el $50 \%$ de los casos y con moderada en el $25 \%$. Se observó necrosis hepática focal en el $75 \%$ de los casos y un $25 \%$ con lisis celular (Figura $N^{\circ} 7$ ).

Entre otras complicaciones, se encontraron: pancreatitis aguda necrótica con peritonitis generalizada en 2 de 10 perros (20\%), neumonía aspirativa (20\%), hemorragia digestiva alta (20\%), hipoglicemia (20\%) y no despertaron de la anestesia (20\%). Estas entidades clínicas constituyeron las causa básicas de muerte.

\section{DISCUSIÓN}

El trasplante de aloinjerto de páncreas (TAP) es una forma de tratamiento de la diabetes mellitus tipo 1 que se realiza en el ámbito internacional desde hace 7 décadas, sola o simultáneamente al trasplante de riñón.

Existen dos tipos principales de trasplante de aloinjerto de páncreas (TAP): el trasplante pancreatoduodenal o total y el trasplante segmental. $\mathrm{La}$ efectividad de una u otra técnica es aún motivo de controversia. Algunos grupos quirúrgicos utilizan el trasplante pancreático-duodenal o total $\left({ }^{2-4.6}\right)$, pese a las dificultades de la técnica ( $\left.{ }^{7}\right)$, dando una morbimortalidad de $63 \%$ frente al trasplante segmental que alcanza una morbimortalidad de $37 \%\left({ }^{8}\right)$.

El manejo adecuado de la secreción pancreática exocrina constituye todavía un problema por investigar. Recientemente se han utilizado en forma experimental varios modelos de drenaje pancreático, entre ellos el drenaje al duodeno, yeyuno, uréter, vejiga, ca-

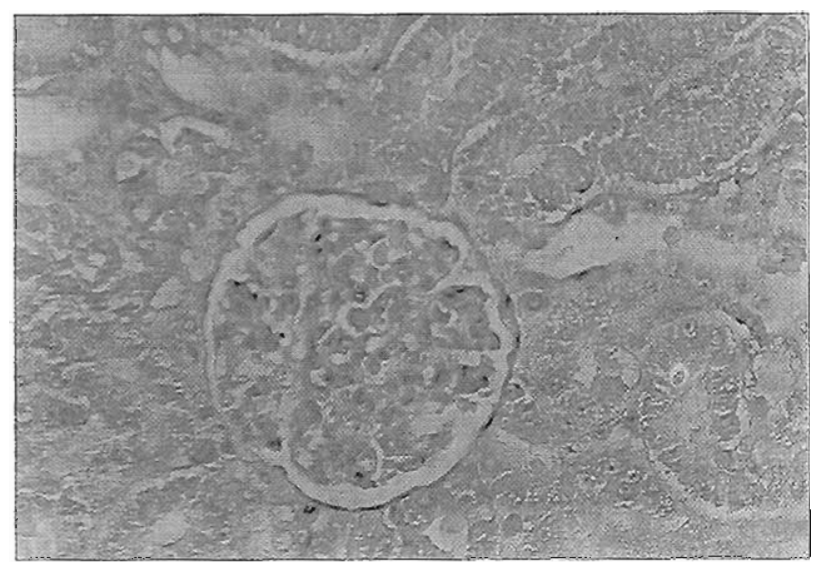

Fig. $\mathrm{N}^{\circ}$ 6.- Microscopía renal del perro receptor (HE 400X). Tubulis renales con edema celular, glomérulo hipercelular y engrosamiento de la membrana basal

(glomerulonefritis membranoproliferativa).

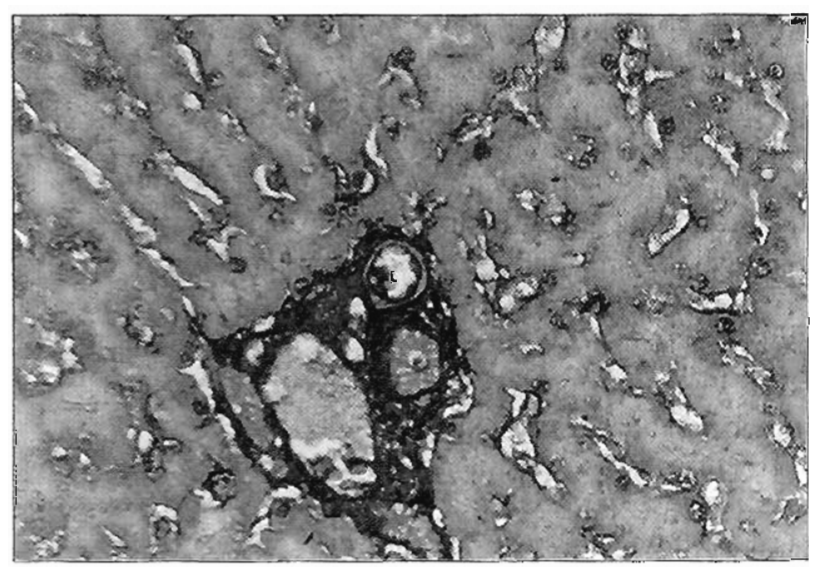

Fig. No 7.- Microscopía hepática del perro receptor (tricrómico de Masson 400X). Moderada distorsión de la arquitectura, células edematizadas y espacio porta con congestión vascular.

vidad peritoneal y oclusión mecánica o química (4.5.8. $\left.{ }^{10}\right)$. Una de las ventajas del drenaje al tracto urinario reside en la posibilidad de diagnosticar precozmente el rechazo al injerto, mediante el dosaje de arailasa urinaria, por lo que el drenaje a uréter o vejiga tiene mejor trascendencia clínica $\left({ }^{4.9 .11 \cdot 14}\right)$. 
Algunos estudios demuestran la posibilidad de efectuar trasplantes de islotes de Langerhans en pacientes con diaberes mellitus tipo 1. Si bien este procedimiento supera las complicaciones del manejo de la secreción pancréatica exocrina, crea una mayor susceptibilidad de rechazo al injerto $\left({ }^{15}\right)$.

En este estudio se realizó el TAP pancreáticoduodenal o total en perros, por la factibilidad de la técnica operatoria, a fin de conocer su eficacia. Se encontró una eficacia en el control de la glicemia de $80 \%$, similar a lo encontrado en humanos por Sollinger y col. $\left({ }^{2,3}\right)$, y Sutherland y col. $\left({ }^{4}\right)$; con un tiempo máximo de sobrevida de 3 días (promedio 19,9 $\pm 6,2$ horas) que difiere ostensiblemente de lo encontrado en perros por Imai y Sato de 12 a 132 días $\left({ }^{16}\right)$, Sato y Tadokoro de 12 a 131 días $\left({ }^{17}\right)$, García y Ortiz, promedio de 30 días $\left({ }^{18}\right)$, y Odor Morales y col., 40 días $\left({ }^{19}\right)$. Estas diferencias en los resultados se pueden explicar por el desarrollo de complicaciones posoperatorias como rechazo hiperagudo, neumonía aspirativa, hemorragia digestiva alta, pancreatitis necrotizante con peritonitis generalizada, hipoglicemia y complicaciones anestésicas; por la toxicidad del aloxano $\left({ }^{20}\right)$ y por la toxicidad de los fármacos inmunosupresores $\left({ }^{16}\right)$.

Se encontró diferencia estadísticamente significativa al comparar las glicemias pre y postrasplante en los perros del grupo receptor. Por otro lado, no se encontró diferencia significativa entre los valores de glicemia basal pre-aloxano y glicemia postrasplante. Ambas comparaciones demuestran directa e indirectamente la función pancreática postrasplante.

El control de glicemia durante las seis primeras horas post-TAP mostró una disminución significativa de la glicemia, que fue más notoria a las 2 horas, a partir de lo cual se incrementó la glicemia levemente, tendiendo a estabilizarse a la sexta hora. Este comportamiento de la glicemia en el posoperatorio inmediato traduce una función pancreática endocrina (con relación a la secreción de insulina) adecuada, principalmente durante las 2 primeras horas postrasplante. Se recomienda que pasadas las dos primeras horas, se regule la glicemia mediante la administración de cloruro de sodio al 0,9\% con el propósito de disminuir el estímulo hiperglicémico para la secreción pancreática de insulina y mantener los islotes de Langerhans en estado de reposo, a fin que puedan sintetizar insulina y formar los gránulos necesarios para su secreción en los estados de hiperglicemia fisiológica.
Respecto a las complicaciones, existe tendencia a la hipoglicemia en el posoperatorio inmediato (20\%), que podría estar en relación con la liberación de insulina, por lo que se recomienda mantener las glicemias en el rango de 100 a $200 \mathrm{mg} / \mathrm{dL}$, utilizando una llave de doble vía con dextrosa al $5 \%$ y cloruro de sodio al $0,9 \%$ que se administrará de acuerdo a las necesidades.

La hemorragia digestiva alta, observada en el $20 \%$ de los casos, puede deberse al estrés producido por la intervención quirúrgica y/o a la administración de altas dosis de corticoides como inmunosupresores, por lo cual se recomienda el uso de bloqueadores $\mathrm{H}_{2}$.

La peritonitis generalizada se produjo como consecuencia de una pancreatitis aguda necrotizante debida a rechazo hiperagudo, que se confirmó por la evaluación clínica y anatomía patológica. Es probable que todos los perros receptores hubiesen llegado a este estado de no intervenir en ellos las otras complicaciones señaladas, ya que el estudio anatomopatólogico de los páncreas trasplantados mostró diferentes grados de rechazo hiperagudo.

La neumonía aspirativa, que se presentó en el $20 \%$ de los casos, se debió a la presencia de vómitos durante y después del acto operatorio, lo que finalmente los llevó a la muerte.

El clorhidrato de ketamina resulta ser un fármaco poco tóxico y aconsejable para inducir la anestesia $\left({ }^{21}\right)$; sin embargo, se pudo apreciar que su efecto fue mayor en perros diabéticos: $20 \%$ de los perros del grupo receptor no despertaron de la anestesia, por lo que se recomienda disminuir las dosis usualmente administradas. Además, debe considerarse el uso de sonda nasogástrica para evitar la neumonía por aspiración.

Del estudio anatomopatológico se desprende que el total del páncreas trasplantado presentó algún grado de distorsión de la arquitectura y signos compatibles con rechazo hiperagudo. Además, en otros órganos.como el hígado, riñón y bazo, se observó diferentes grados de lesión que pueden deberse a la acción tóxica del aloxano $\left({ }^{20}\right)$ o a la repercusión sistémica del rechazo al trasplante.

La dosis más efectiva para producir DME permanente fue $150 \mathrm{mg} / \mathrm{kg}$ a diferencia de lo encontrado por Houssay, que fue $100 \mathrm{mg} / \mathrm{kg}$. No obstante, esta dosis mayor fue tóxica ya que produjo diferentes grados de necrosis en los órganos (hígado, bazo y riñón). 
Pese a la administración de un esquema triple de inmunosupresión. todos los perros receptore's presentaron algún grado de rechazo, lo cual podría deberse a la vía de administración enteral en vez de parenteral de los fármacos (ciclosporina y azatioprina) que no garantiza uná buena absorción.

\section{CONCLUSIONES}

1. El trasplante de aloinjerto de páncreas total fue eficaz en disminuir la glicemia en perros con DME. La sobrevida, sin embargo, fue baja debido al rechazo hiperagudo y a la toxicidad del aloxano.

2. El trasplante de aloinjerto de páncreas produjo disminución de la glicemia en el posoperatorio inmediato, que fue más notoria en las primeras dos horas y tendió a estabilizarse en la sexta hora.

3. La dosis de aloxano más eficaz en producir diabetes mellitus experimental permanente fue $150 \mathrm{mg} / \mathrm{kg}$ i.v.; no obstante, resultó ser tóxica y contribuyó a aumentar la morbilidad.

4. Las complicaciones posoperatorias del trasplante de aloinjerto de páncreas favorecieron la baja sobrevida del perro receptor.

\section{AGRADECIMIENTOS}

Los autores expresan su agradecimiento por su colaboración, sugerencias y estímulo a los doctores: Ramiro Gonzalez, María Valcárcel. Juan Armanza, Gerardo Ronceros, Carlos Delgado, David Diaz Leyva, Pedro Larrea, Carmen Torres de Gutierrez, Mauro Mateo, Aníbal Carrasco y al Si. Ricardo Palacios.

Este trabajo se llevó a cabo bajo el auspicio de las siguientes instituciones: Consejo Nacional de Ciencia y Tecnología (CONCYTEC) [Partida No 824-10-95 OAI], Banco de Organos Hospital Edgardo Rebagliati Martins, Instituto de Anatomía Patológica UNMSM, Servicio de Hematología del Hospital Nacional Dos de Mayo, Servicio de Bioquímica del Hospital Nacional Dos de Mayo, Sandoz del Perú S.A., Schering Plough, Upjohn, Elly Lilly, Roche, Abeefe, Carrión, Parke Davis, Boehringer, Química Suiza, y Cirugía Peruana S.A.

\section{BIBLIOGRAFIA}

I) Gayet R, Guillaumine M. La rcgulation de la sccresion internc pancreatique par un processus normalisatcu denosiree pardes transplaniation de pancreas. Cr Soc Biol 1977; 97: 1613-27.

2) Sollinger $I X W$, Knechtle $S J$, Recd $\Lambda$, D'Alessandro AM, Kalayoglu M, Belzer FO, Pirsch J. Experience with 100 consecutive simultancous kidncy-pancreas transplants with bladder drainage. Ann Surg 1991 Dic: 214(6):703-11.

3) Sollinger HW, Stratta RJ, D'Alessandro AM, Kalayoglu M, Pirsch JD, Belzer FO. Experience with simultaneous pancreaskidney transplantation. Ann Surg 1988 Oct; 208(4):475-83.

4) Sutherland DE, Dunn DI, Goetz FC, Kennedy W, Ramsay RC, Steffes MW y col. A 10-year experience with 290 pancreas transplants at a single institution. Ann Surg 1989 Sep; $210(3): 274-85$

5) Seclen S, Rojas MI, Nuñez O,Valdívia H y col. Type I (insulin - dependent) diabetes in mestizo children of Lima, Perú. Report on a seven ycars $(1985-1991)$ incidence. Diabelologia 1994; 37(Suppl 1):597.

6) Groth CG. Pancreatic transplantation. Groth C. G. Editor 1988 Sauthers Company.

7) Joslin's y col.: Diabetes MellitusPhiladelphia; Lea \& Febigcr. $12^{\text {th }}$ cd: ${ }^{\circ} 1985$.

8) Dubernaid JM, Sutherland DE. International Handbook of Pancreas transplantation, 1989, Kluwer Academic Publischers.

9) Sutherland DE. Pancrcatic transpiantation: state of the art. Transplant Proc 1992 Jun: 24(3):762-6.

10) Sutherland DE, Dunn DL, Moudry-Munns K, Gillingham K, Najarian JS. Pancreas transplants in nonurenic and posturemic diabetic patients. Transplant PToc 1992 Jun; 24(3):780-1.

11) Sutherland DE, Gruessner R, Gillingham K, Moudry-Munns $\mathbf{K}$, Dunn D, Brajman K y col. A single institution's experience with solitary pancreas transplantation: a multivariate analysis of factors leading, to improved outcome. Clin Transpl 1991; 3 (15): $14 !-52$

12) Moundry-Munns KC, Gillinham K, Dunn DL, Sutherland DE. Mortality risk for lechnically successful and causcs of death. Transplant Proc 1992; 24(3):8632-50.

13) Stephanian E, Gruessner RW, Brayman KL, Gores P, Dunn DL, Sutherland DE. Converting exocrine drainage from bladder to bowe! in recipients of whole pancreaticoduodenal transplants. Transplants Proc 1992; 24(3):803-10.

14) Martin X, Lefrancois N, Choukair M, Dawahra M, SousaCabello A, Marechal JM, Dubernard JM. Segmental versus total duodenopancreatic grafts: A two-yeal randonized study. Transplant Proc 1992: 24(3):782-3.

15) Schwartz, Shires, Spencer. Principios de Cirugia. Mexico; Editorial Interamericana, 5a ed: 1991.

16) Imai K, Sato K, Nakayama $Y$, Takishima $T$, Osakabe $T$, Yokota K y col. Histopathological sludy of canine pancreaticoduodcnal allotransplantation with FK506. cyclosporinc, and triple regimen immunosuppression. Transplant Proc 1991 Feb; 23(1 Pt 2):1589-92. 
17) Sato K, Imai K, Tadokoro F, Ishida K, Matsuzawa K, Matsui $\mathrm{T}$, Ishida $\mathrm{K}$ y col. Effectiveness of triple regimen inmmunosuppression in canine pancreatic allotransplantation. Transplant Proc. 1994 Aug; 26(4):2281-4.

18) Garcia FA, Ortiz de Solorzano J y col. Respuesta endocrina y metabólica inmediata al transplante segmentario de páncreas canino. Archivos de la Facultad de Medicina de Zaragoza. 1989; 29(3): $147-51$.
19) Odor-Morales A, Lopez RM, Luque E, Chavira SC, Sotres $A$, Larriva $J$ y col. Urinary amylase, urinary insulin, or urinary thromboxane: which is the best predictor of pancreatic allograft rejection in the dog? Transplant Proc, 1990 Apr; 22(2):709-11.

20) Houssay, Bernardo AM. Alloxan diabeles. Can Mcd Assoc J 1947; 56:519.23.

21) Pelli R, Cartagena E y col. Anestesia General con perfusión de Kelamina en cirugía experimental. Rev Argent Cirug 1985; 48(34): $153-5$. 